\title{
Characterization and stability studies of emulsion systems containing pumice
}

\author{
Marilene Estanqueiro,"*, Jaime Conceição ${ }^{1}$, Maria Helena Amaral ${ }^{1}$, Delfim Santos ${ }^{1}$, \\ João Baptista Silva ${ }^{2}$, José Manuel Sousa Lobo ${ }^{1}$
}

\begin{abstract}
${ }^{1}$ Research Centre for Pharmaceutical Technology, Laboratory of Pharmaceutical Technology, Department of Drug Sciences, Faculty of Pharmacy, University of Porto, Porto, Portugal, ${ }^{2}$ Research Unit "GeoBioTec", University of Aveiro, Campus
\end{abstract}

Universitário de Santiago, Aveiro, Portugal

\begin{abstract}
Emulsions are the most common form of skin care products. However, these systems may exhibit some instability. Therefore, when developing emulsions for topical application it is interesting to verify whether they have suitable physical and mechanical characteristics and further assess their stability. The aim of this work was to study the stability of emulsion systems, which varied in the proportion of the emulsifying agent cetearyl alcohol (and) sodium lauryl sulfate (and) sodium cetearyl sulfate (LSX), the nature of the oily phase (decyl oleate, cyclomethicone or dimethicone) and the presence or absence of pumice $(5 \% \mathrm{w} / \mathrm{w})$. While maintaining the samples at room temperature, rheology studies, texture analysis and microscopic observation of formulations with and without pumice were performed. Samples were also submitted to an accelerated stability study by centrifugation and to a thermal stress test. Through the testing, it was found that the amount of emulsifying agent affects the consistency and textural properties such as firmness and adhesiveness. So, formulations containing LSX $(5 \% \mathrm{w} / \mathrm{w})$ and decyl oleate or dimethicone as oily phase had a better consistency and remained stable with time, so exhibited the best features to be used for skin care products.
\end{abstract}

Uniterms: Emulsions/topical use/stability study. Emulsions/topical use/characterization. Pumice/presence in emulsions. Emulsions/texture. Emulsions/rheology. Emulsions/spreadability.

Emulsões são a forma de apresentação mais comum dos produtos para aplicação na pele. No entanto estes sistemas podem exibir alguma instabilidade. Por esta razão, quando do desenvolvimento de emulsões para aplicação tópica é importante verificar se estas apresentam propriedades físicas ou mecânicas adequadas e avaliar a sua estabilidade. O objetivo deste trabalho consistiu no estudo da estabilidade de emulsões, cujas variações entre elas foi a proporção de agente emulsificante álcool estearílico (mais) laurilsulfato de sódio (mais) estearilsulfato de sódio (LSX), a natureza da fase oleosa (decil oleato, ciclometicona ou dimeticona) e a presença ou ausência de pedra-pomes $(5 \% \mathrm{~m} / \mathrm{m})$. Mantendo as amostras à mesma temperatura, realizaram-se o estudo da reologia, a análise de textura e observação microscópica das formulações com e sem pedra-pomes. Amostras foram, também, submetidas a estudo de estabilidade acelerada por centrifugação e a ensaio de estresse térmico. Através dos testes realizados, constatou-se que a quantidade de agente emulsificante influencia a consistência e as propriedades de textura, como a firmeza e a adesividade. As formulações contendo LSX $(5 \% \mathrm{~m} / \mathrm{m})$ e decil oleato ou dimeticona como fase oleosa exibiram melhores caraterísticas como produtos para aplicação na pele, uma vez que estas formulações apresentaram menor firmeza e consistência e permaneceram estáveis com o tempo.

Unitermos: Emulsões/uso tópico/estudo da estabilidade. Emulsões/uso tópico/caracterização. Pedrapome/presença em emulsões. Emulsões/textura. Emulsões/reologia. Emulsões/espalhabilidade.

\footnotetext{
*Correspondence: M. S. R. Estanqueiro. Laboratório de Tecnologia Farmacêutica, Centro de Investigação em Tecnologia Farmacêutica, Departamento das Ciências do Medicamento, Faculdade de Farmácia, Universidade do Porto. Rua de Jorge Viterbo Ferreira, n.228, Edifice 3, 4050-313 - Porto, Portugal. E-mail:msrestanqueiro@ff.up.pt
} 


\section{INTRODUCTION}

Emulsions are the most common forms of skin care products (Epstein, 2009). By definition, an emulsion is a heterogeneous system of two or more immiscible liquids in which one is dispersed in the other (Epstein, 2009).

Emulsions used in personal care application, both oil-in-water $(\mathrm{O} / \mathrm{W})$ and water-in-oil $(\mathrm{W} / \mathrm{O})$ type, need to satisfy a number of criteria, such as having the right consistency (rheology) for skin application, feeling good on the skin, having good spreadability, long-term (2-3 years) physical stability under various conditions (temperature variation, stress induced by vibration during transportation, among others) and safety of ingredients in order to not induce skin irritation or any adverse effects (Lemaitre-Aghazarian et al., 2004; Tadros, 2004). Emulsions used in personal care application vary in their consistency from "fluid-like" consistency (as is the case of many lotions) to "semi-solid" consistency (Tadros, 2004). A properly formulated vehicle is critical for the effective delivery of the desired substances to the skin (Epstein, 2009).

The purpose of stability testing is to provide information about how the quality of product varies with time under the influence of some environmental factors like temperature, humidity and light. This information lead to setting the shelf-life of pharmaceutical products and cosmetics (Abdulkarim et al., 2010).

Since emulsions are biphasic systems, they are inherently unstable according to the second law of thermodynamics, and the degree and speed of destabilization vary from system to system. So, it is important for a formulator to carry out studies on the stability of the developed systems (Abdulkarim et al., 2010).

In stability tests, the samples are periodically checked for changes and important features (Almeida, Bahia, 2006). The protocols proposed by the International Conference on Harmonization (ICH) foresee the storage of samples at different temperatures, namely, room temperature and higher (ICH, 2003). Temperature has an important effect on viscosity (Almeida, Bahia, 2006).

Rheological studies have also been used to predict the behavior of products and provide information to improve stability and general performance (Almeida, Bahia, 2006).

Stability tests are usually conducted at constant temperatures, but tests under conditions that are periodically changed can reveal inadequacies more quickly than storage at constant temperature (Almeida, Bahia, 2006). So, in the initial stages of the development process, for screening purposes, cyclic tests can provide useful information (Cannell, 1985).

The aim of this study was to evaluate the influence of the amount of emulsifying agent as well as the oily phase composition on the mechanical characteristics of emulsions with and without pumice (grain size less than $63 \mu \mathrm{m})(5 \%$ $\mathrm{w} / \mathrm{w}$ ) and analyze their stability under different conditions.

Pumice is a volcanic rock formed during explosive volcanic eruptions of acidic and highly viscous magma; it is an extremely vesicular (vesicles are bubble-shaped openings formed by the expansion of entrapped gases), frothy, natural glass having a high (60-75\%) silica content and very low density and in some cases floats on water. It consists of fragile acicular glass and minerals (in particular, feldspars). Pumice ground into micro-fine grains provides an excellent exfoliating medium to remove dead and rough skin (Estanqueiro et al., 2012). In this case, particle sizes less than $63 \mu \mathrm{m}$ have no abrasive action. However, pumice can be a potential anti-irritant agent, due to its high content of silica dioxide. Additionally, finely divided solid particles of pumice stone can potentially contribute to stability increasing of emulsions.

\section{MATERIAL AND METHODS}

\section{Material}

Cetearyl alcohol (and) sodium lauryl sulfate (and) sodium cetearyl sulfate (LSX), decyl oleate, 5-chloro-2methyl-4-isothiazolin-3-one and 2-methyl-4-isothiazolin3-one (KCG), dimethicone and cyclomethicone were obtained from Acofarma (Spain). Propylene glycol and nicotinamide were purchased from J. Vaz Pereira (Portugal) and imidazodinyl urea was purchased from Guinama (Spain). Pumice stone have various geologic occurrences in São Miguel Island, Azores Archipelago, Portugal.

\section{Methods}

\section{Preparation of emulsions}

The composition of the developed formulations is presented in Table I. Formulations were prepared by heating the aqueous and oily phases at $60-70{ }^{\circ} \mathrm{C}$. When the two phases were at the same temperature, the aqueous phase was slowly added to the oily phase, with a stirring speed of 500-600 rpm. Stirring was maintained until cooling. Then, pumice $(5 \% \mathrm{w} / \mathrm{w})$ was added by mechanical stirring, one day after the emulsion preparation. Formulations were stored in plastic containers at room temperature. 
TABLEI - Composition of developed formulations (\%,w/w)

\begin{tabular}{lcccccccc}
\hline Ingredients & FB1 & FP1 & FB2 & FP2 & FB3 & FP3 & FB4 & FP4 \\
\hline LSX & 10 & 10 & 5 & 5 & 5 & 5 & 5 & 5 \\
Decyl oleate & 15 & 15 & 15 & 15 & -- & -- & -- & -- \\
Dimethicone & -- & -- & -- & -- & -- & -- & 15 & 15 \\
Cyclomethicone & -- & -- & -- & -- & 15 & 15 & -- & -- \\
Pumice \# $<63 \mu \mathrm{m}$ & -- & 5 & -- & 5 & -- & 5 & -- & 5 \\
Nicotinamide & 3.5 & 3.5 & 3.5 & 3.5 & 3.5 & 3.5 & 3.5 & 3.5 \\
Propylene glycol & 20 & 20 & 20 & 20 & 20 & 20 & 20 & 20 \\
Imidazodinyl urea & 0.2 & 0.2 & 0.2 & 0.2 & 0.2 & 0.2 & 0.2 & 0.2 \\
KCG & 0.1 & 0.1 & 0.1 & 0.1 & 0.1 & 0.1 & 0.1 & 0.1 \\
Purified water & q.s.100 & q.s.100 & q.s. 100 & q.s. 100 & q.s. 100 & q.s. 100 & q.s. 100 & q.s. 100 \\
\hline
\end{tabular}

During the experimental work it was decided that the influence of internal phase (decyl oleate, cyclomethicone or dimethicone) with $5 \%$ of emulsifying agent should be evaluated, because with $10 \%$, they had too thick of a consistency. Hence, only FB1 and FP1 formulations have been tested with $10 \%$ of LSX.

\section{Characterization and real-time stability prediction}

Rheological and textural analyzes of the prepared formulations, which were maintained at room temperature, were performe done week, one and two months after their preparation. For rheological analysis, a rotational viscometer Brookfield model DV-E (Germany) was used. Spindle number 6 was used (except for FB3 and FP3 formulations, where spindle number 5 was used) to obtain a torque greater than $10 \%$ and less than $100 \%$ for the following speeds: 4.0, 5.0, 10.0, 12.0, 20.0 and $30.0 \mathrm{rpm}$. For each speed, the apparent viscosity values (mPa.s) were recorded.

The textural analyzes were performed in the compression mode using a texturometer (Stable Micro Systems TA-XT2i, United Kingdom) by carrying out a penetration test using a load cell of $5 \mathrm{~kg}$, a cylindrical probe (13 $\mathrm{mm}$ diameter in the case of FB1, FP1, FB2, FP2, FB4 and FP4 formulations, and $25 \mathrm{~mm}$ diameter in the case of FB3 and FP3 formulations, since these two formulations were less viscous than the others), a penetration depth of $5 \mathrm{~mm}$, test speed of $3 \mathrm{~mm} / \mathrm{s}$ and a trigger force of $0.049 \mathrm{~N}$. From the obtained graph force versus distance, the maximum force $(\mathrm{N})$ (firmness) and negative area $(\mathrm{N} \cdot \mathrm{mm})$ (adhesiveness) were calculated. All measurements were performed in triplicate.

Since the spreading of a cream is a determinant textural attribute that governs the performances of the product during its application on skin (Savary et al.,
2013), spreadability evaluation was performed using a texturometer (Stable Micro Systems TA-XT2i, United Kingdom), with a TTC spreadability test probe, a penetration depth of $23 \mathrm{~mm}$, a test speed of $3.0 \mathrm{~mm} / \mathrm{s}$ and post-test speed of $10.0 \mathrm{~mm} / \mathrm{s}$. In this test, the sample is placed into the female cone, avoiding the incorporation of air. The sample surface is leveled, the probe placed at a defined position $(25 \mathrm{~mm})$ and the assay starts with the male cone's downward movement $(23 \mathrm{~mm}$ penetration and a speed of $3 \mathrm{~mm} / \mathrm{s}$ ), which compresses the sample, promoting its scattering between the surfaces of the two cones.

Microscopic observations were performed with a Nikon Eclipse E400 microscope (Japan), with a magnification of $400 \mathrm{x}$, and images were captured by an attached Nikon Coolpix MCD camera (Japan).

\section{Accelerated stability studies}

- Centrifugation test (mechanical stress)

For pre-screening purposes, regarding the physical stability and also to gain stability prognoses, $6 \mathrm{~mL}$ samples of each formulation were submitted to three cycles of $3000 \mathrm{rpm}$ for the duration of 30 minutes. At the end of each cycle the samples were checked to see whether there was any change.

- Thermal stability test

A heating/cooling cycle test was performed and the formulations were stored in a fridge/oven and temperature was changed, respectively, between 4 and $40{ }^{\circ} \mathrm{C}$ every $24 \mathrm{~h}$, for the duration of 7 days. This thermal stress test was performed one month after preparation of formulations. Textural and colorimetric analysis was performed before and after the thermal stress. In the initial stages of the development, for screening purposes, these tests can 
provide useful information about stability prognosis (Ondracek et al., 1985; Almeida, Bahia, 2006).

Textural analysis was performed under the same conditions as described above. Colorimetric analysis was carried out using a colorimeter (Minolta CR-400, Japan). The obtained values of each parameter of the $\mathrm{L}^{*} \mathrm{a} * \mathrm{~b} *$ color space are the average of three measurements.

\section{RESULTS AND DISCUSSION}

\section{Characterization and real time stability prediction}

Figure 1 shows the results of viscosity as a function of speed (rheological behavior) of all formulations, determined one week, one month and two months after their preparation after storage at $20^{\circ} \mathrm{C}$.

Rheological studies showed that all formulations presented a pseudoplastic behavior, but without thixotropy. Only FP1 and FP2 formulations presented thixotropy after the first week of storage, experiencing a loss of this property over time. The pseudoplastic flow is the most common behavior of dermatological formulations, since the pseudoplastic material can break down for easy spreading and the applied film can gain viscosity instantaneously to running resist (Corrêa et al., 2005; Laba, 1993; Gaspar, Campos, 2003).

The formulations with lower amount $(5 \% \mathrm{w} / \mathrm{w})$ of LSX have lower apparent viscosity than FB1 and FP1 formulations $(10 \% \mathrm{w} / \mathrm{w})$. The formulations with cyclomethicone (FB3 and FP3) show considerably lower values of viscosity than the formulations with decyl oleate and dimethicone, with the same amount of LSX. Tamburic and co-workers (1996) have also observed an increase of viscosity related to the rise of surfactant concentration in their studies. Formulations containing pumice present greater viscosity than the corresponding formulations without pumice. This can be due the fact that solid particles of pumice remaining in the external phase of $\mathrm{O} / \mathrm{W}$ emulsion, increase the viscosity (Lagaly et al., 1999). The consistency of an emulsion can be controlled by addition of various rheological modifiers such as "thickeners" (e.g. polysaccharides) or finely divided inert solids (such as silica and bentonite clays) (Tadros, 2004). Various authors have studied the effect of finely divided solids on the rheology and stability of emulsions (Pichot et al., 2009; Lagaly et al., 1999; Torres et al., 2007; Arditty et al., 2004). As was previously observed by Lagaly and co-workers (1999), clay mineral particles remaining in the external phase increase the apparent viscosity, which reduces the mobility of droplets and improves the stability of emulsions. This may be due to the fact that clay minerals aggregate in three dimensional networks. In general, the formulations experienced a small decrease in apparent viscosity with time.

Figure 2 shows the results for firmness and adhesiveness determined one week, one month and two months after preparation and storage at $20^{\circ} \mathrm{C}$. FB1 and FP1 showed higher firmness that FB2, FP2, FB4 and FP4. This may be due to the fact that FB1 and FP1 contain twice as much LSX than the other formulations. The same was observed for the adhesiveness values. At the end of two months we observed that there are no considerable differences between the formulations with and without pumice, concerning the firmness values.

Formulation FP3 suffered greater variation of firmness after two months.

In relation to adhesiveness, the formulations that suffered a greater variation after two months, with diminution of negative area values, are FB1, FP1 and FP2. Formulations FP2 and FP4 show adhesiveness values similar to their bases (formulations without pumice) and formulations with dimethicone have more adhesiveness than formulation with decyl oleate.

Relatively to cyclomethicone formulations, FP3 shows greater adhesiveness than FB3.

Formulations which have been designed for topical application must exhibit acceptable mechanical characteristics, namely, ease of application, low firmness and suitable adhesiveness to enable formulation adhesion on the skin (Almeida, Bahia, 2006). Firmness is related to the ease of product removal from a container and ease of application onto a substrate, whereas adhesiveness, a property related to bioadhesion, describes the relative adhesive properties of a formulation (Jones et al., 1997).

It is possible to verify that viscosity, firmness and adhesiveness varies in a proportional manner. Texture can be regarded as a manifestation of the rheological properties of a product (Almeida, Bahia, 2006). Texture is an important attribute that affects processing and handling, shelf-life and consumer acceptance of products (Almeida, Bahia, 2006).

Figure 3 shows the spreadability results of all formulations. The results were interpreted as the difficulty of spreading; instrumental spreading was measured as a force that is proportional to the difficulty to spread the product (Savary et al., 2013). As can be seen in Figure 3 there are no considerable differences between formulations containing pumice regarding the spreadability. To achieve adequate efficacy and user acceptance of an emulsion, spreadability is an important property (Savary et al., 2013).

Figures 4, 5, 6 and 7 refer to photographs of preparations observed microscopically. The images 

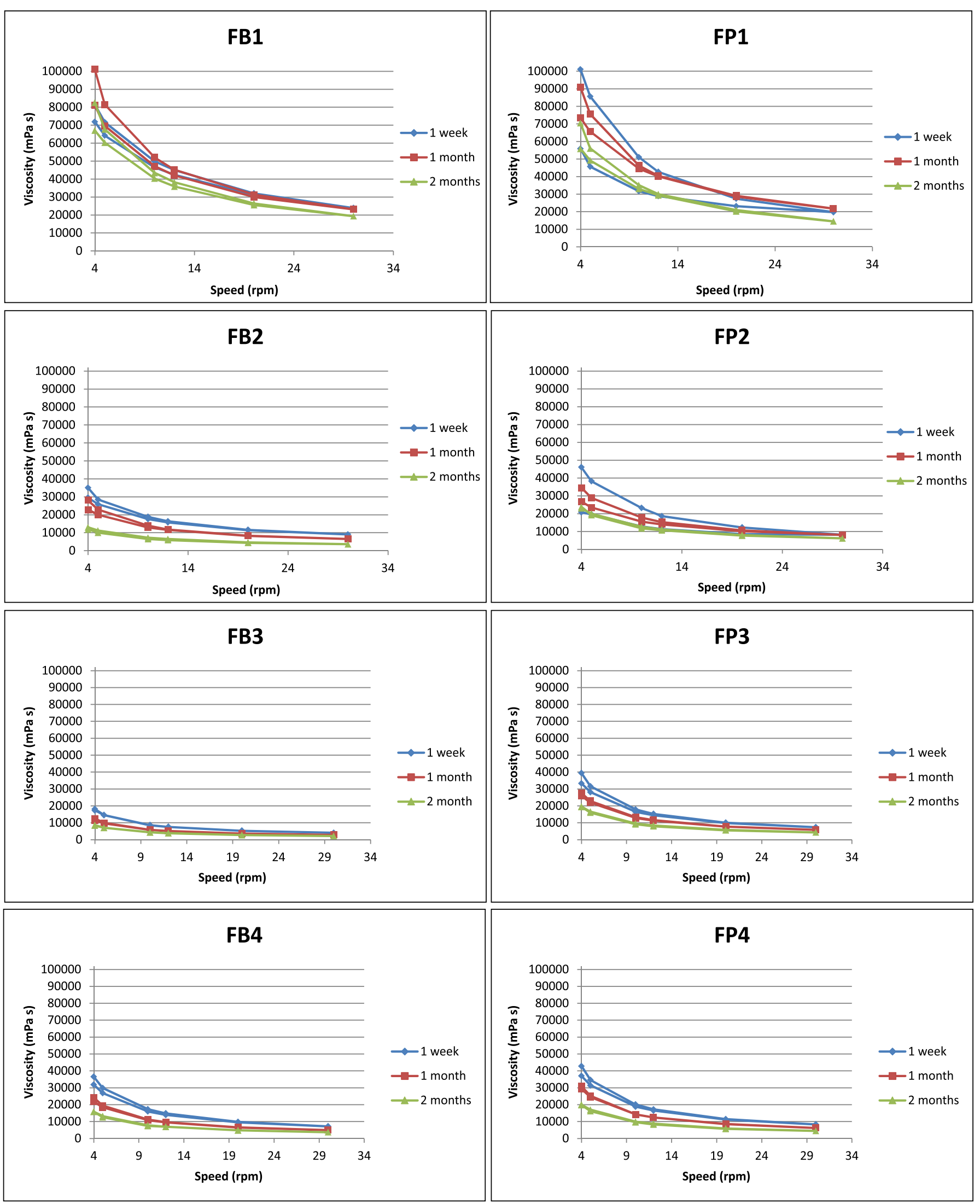

FIGURE 1 - Rheological behavior of each formulation determined one week, one month and two months after formulation's preparation, maintained at $20^{\circ} \mathrm{C}$. 

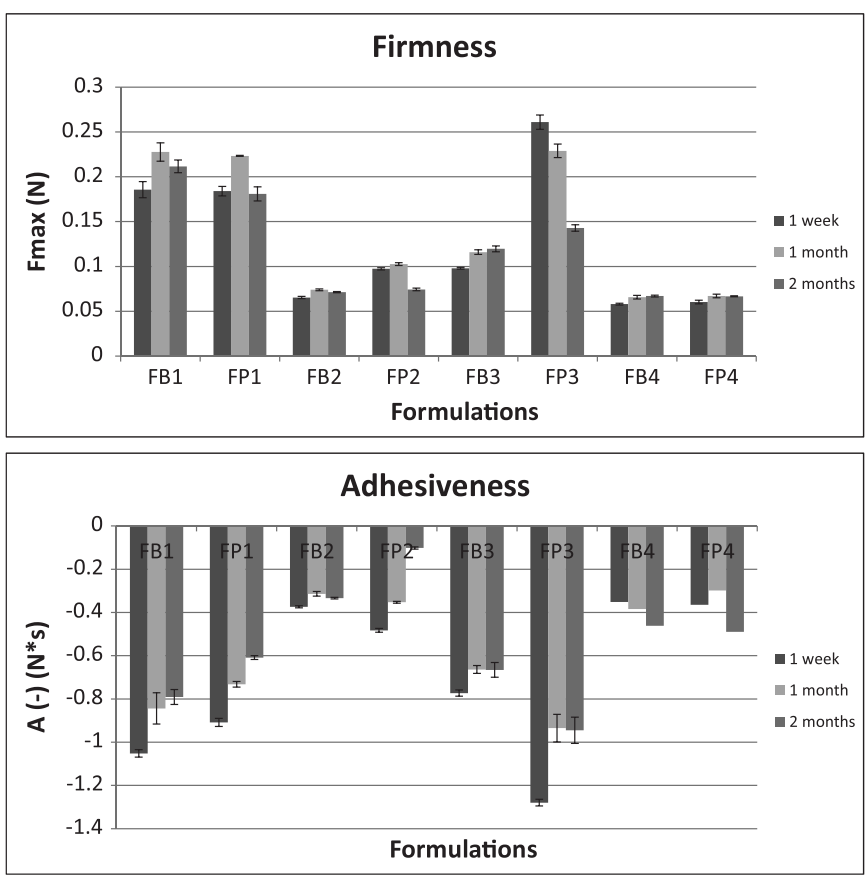

FIGURE 2 - Variation of firmness and adhesiveness (mean of three results) of formulations, stored at $20^{\circ} \mathrm{C}$ during two months. Formulations FB3 and FP3 were analyzed using a $25 \mathrm{~mm}$ probe while the other formulations were analyzed with a $13 \mathrm{~mm}$ probe.

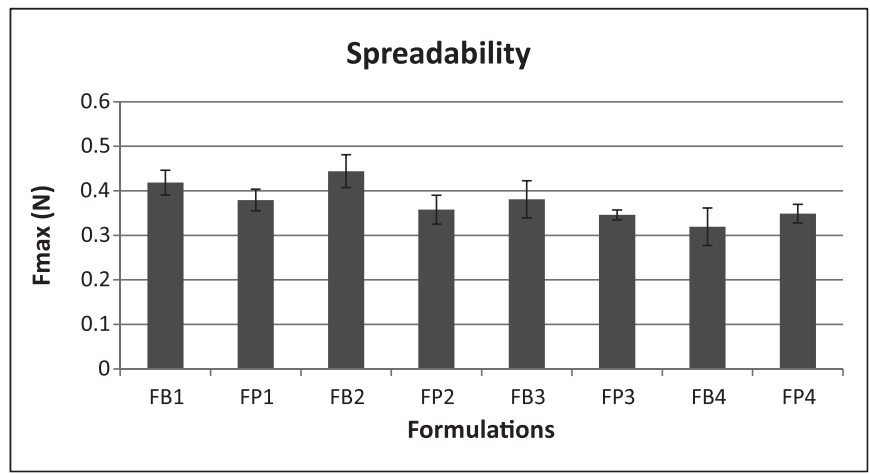

FIGURE 3 - Spreadability values of formulations (mean of three results). The results were interpreted as the difficulty of spreading.
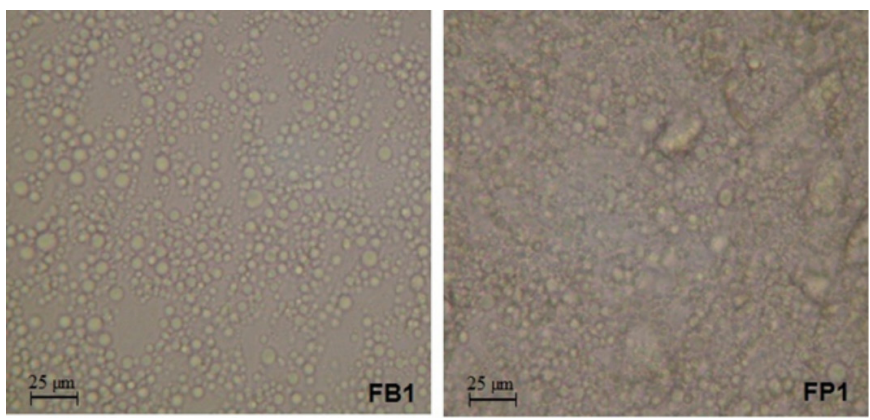

FIGURE 4 - Microscopic images of FB1 and FP1 formulations.
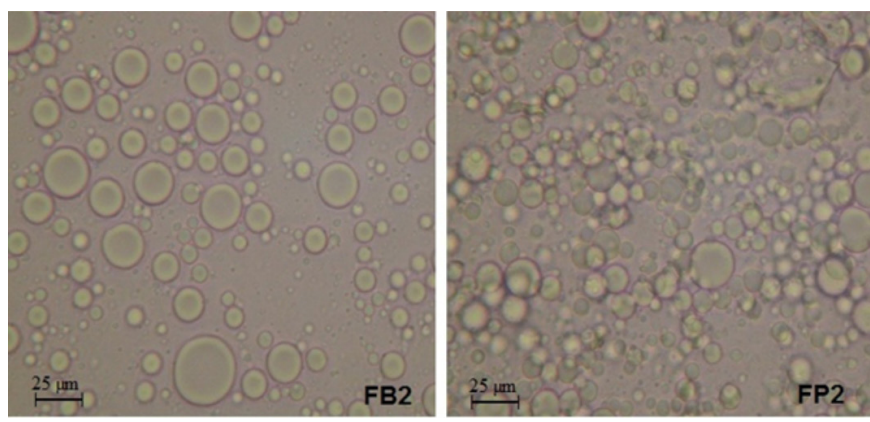

FIGURE 5 - Microscopic images of FB2 and FP2 formulations.
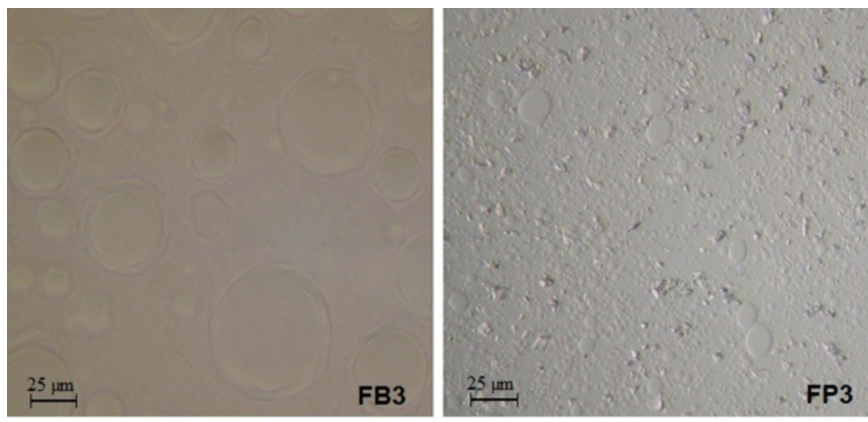

FIGURE 6 - Microscopic images of FB3 and FP3 formulations.

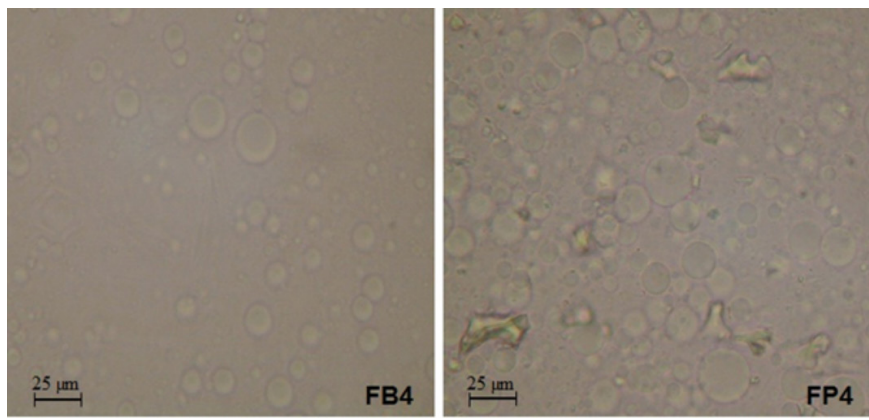

FIGURE 7 - Microscopic images of FB4 and FP4 formulations.

provide information on the structure and particle size of the emulsified systems.

All figures show individuality droplets of internal phase. Additionally, in the images of FP1, FP2, FP3 and FP4 formulations, pumice particles can be seen. The size of droplets differs substantially between formulations and FB3 shows larger droplets, apparently presenting coalescence. The droplet size of emulsions is a major characteristic of the efficiency of the constituent emulsifier. To yield stable emulsions, a good emulsifier should allow the formation of the smallest droplets (Shi et al., 1999). Additionally, as was described by Chanamai and co-workers (2000), the rheology of $\mathrm{O} / \mathrm{W}$ emulsions is strongly influenced by the droplet size and concentration. In this case, emulsions containing smaller droplets and 
greater concentration of droplets (FB1 and FP1) showed greater apparent viscosity than emulsions containing larger droplets (FB3 and FP3).

\section{Accelerated stability}

\section{Centrifugation test (mechanical stress)}

At the end of each cycle of $3000 \mathrm{rpm}$ of 30 minutes duration samples were checked for some instability phenomena. After the first cycle, formulations FP2, FP3 and FP4 showed pumice deposition. However, there were no other changes after the three centrifugation cycles. Ondracek and co-workers (1985) have concluded that preparations which withstand a high mechanical load generally showed more stability than those which do not show this property.

\section{Thermal stability test}

Figure 8 illustrates the results of firmness and adhesiveness obtained before and after the thermal stress.

Through graph analysis it can be seen that formulations FB1, FP1, FB2 and FP2 presented a greater variation of firmness with thermal cycle. In relation to adhesiveness, only formulations FB1 and FP1 presented greater variation. For all the other formulations there are no differences between the first and the seventh days.

Table II shows the results of each $\mathrm{L}^{*} \mathrm{a} * \mathrm{~b} *$ coordinates for all formulations determined before and after thermal stress.

Formulations' color was conveniently measured instrumentally using reflectance methods. Reflectance colorimetry takes advantages of the CIEL*a*b* standardized systems in the $\mathrm{L}^{*} \mathrm{a}^{*} \mathrm{~b}^{*}$ color space modifications. $\mathrm{L}^{*}$ value is expressed on a scale ranging from 0 for black to 100 for white. $\mathrm{a}^{*}$ and $\mathrm{b}^{*}$ indicate two perpendicular color axes, varying between -60 and +60 , with $a^{*}$ ranging
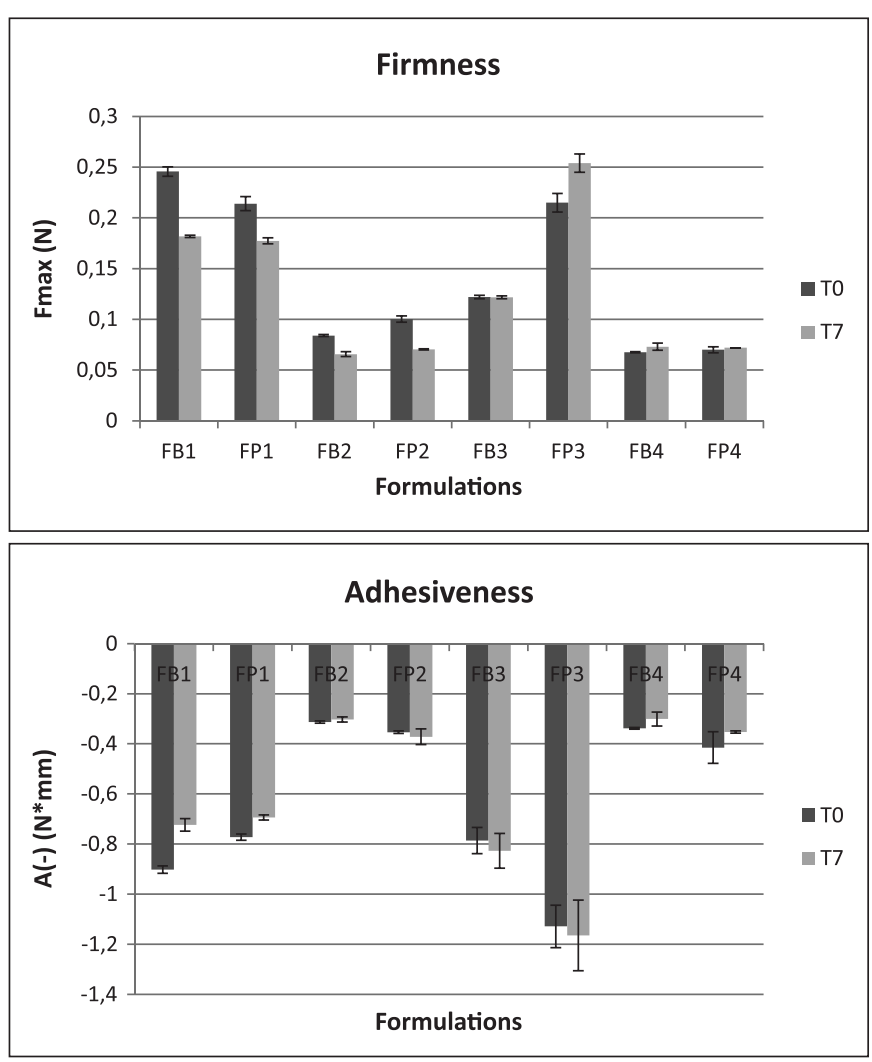

FIGURE 8 - Results of firmness and adhesiveness obtained before (T0) and after (T7) thermal stress. Formulations FB3 and FP3 were analyzed using a $25 \mathrm{~mm}$ probe while the other formulations were analyzed with a $13 \mathrm{~mm}$ probe.

between green and red and $b^{*}$ ranging between blue and yellow (Devillers et al., 2010). From the observations in Table III there is no consistent variation of any parameter of the $\mathrm{L}^{*} \mathrm{a} * \mathrm{~b} *$ color space after submitting the samples to thermal stress. It is interesting to observe that formulations FB3 and FB4 present negative values of $b^{*}$. Relatively to $\mathrm{a}^{*}$ parameter, the formulations containing pumice have

TABLE II - Results of L*a*b* color space parameters, determined before (T0) and after (T7) a thermal stress

\begin{tabular}{|c|c|c|c|c|c|c|}
\hline \multirow{2}{*}{ Formulations } & \multicolumn{3}{|c|}{ T0 } & \multicolumn{3}{|c|}{$\mathrm{T} 7$} \\
\hline & $a^{*}$ & $\mathbf{b}^{*}$ & $L^{*}$ & $a^{*}$ & $\mathbf{b}^{*}$ & $\mathbf{L}^{*}$ \\
\hline FB1 & -1.27 & 1.44 & 83.3 & -1.28 & 1.45 & 83.01 \\
\hline FP1 & 0.1 & 6.18 & 67.98 & 0.11 & 6.55 & 66.23 \\
\hline FB2 & -1.43 & 0.76 & 78.24 & -1.41 & 0.66 & 75.83 \\
\hline FP2 & 0.01 & 6.24 & 66.11 & 0.09 & 7.09 & 61.23 \\
\hline FB3 & -0.47 & -6.18 & 44.96 & -0.65 & -6.75 & 44.69 \\
\hline FP3 & 0.14 & 6.2 & 55.9 & -0.02 & 6.06 & 54.27 \\
\hline FB4 & -0.61 & -4.31 & 58.55 & -0.69 & -4.48 & 56.75 \\
\hline FP4 & 0.15 & 6.61 & 56.36 & 0.06 & 6.31 & 55.08 \\
\hline
\end{tabular}


positive values and the formulations without pumice have negative values.

\section{CONCLUSIONS}

Formulations FP2 and FP4 exhibit the best features for application on the skin, since these formulations showed less firmness and thinner consistency (rheology) which represents a lower force needed to promote their uniform application on skin surface. Regarding stability, formulation FP4 remained more stable over the time (two months) and under adverse conditions like temperature and mechanical stress.

\section{ACKNOWLEDGEMENTS}

Authors would like to thank to "PROCONVERGÊNCIA Program" from Secretaria Regional da Economia da Região Autónoma dos Açores and "TERMAZ" Project promoted by INOVA (Instituto de Inovação Tecnológica dosAçores) for providing pumice and financial the investigation.

\section{REFERENCES}

ABDULKARIM, M.F.; ABDULLAH, G.Z.; CHITNENI, M.; MAHDI, E.S.; YAM, M.F.; FAISAL, A.; SALMAN, I.M.; AMEER, O.Z.; SAHIB, M.N.; ABDULSATTAR, M.Z.; BASRI, M.; NOOR, A.M. Stability studies of nano-cream containing piroxicam. Int. J.Drug Delivery, v.2, n.4, p.333339, 2010.

ALMEIDA, I.F.; BAHIA, M.F. Evaluation of the physical stability of two oleogels. Int. J. Pharm., v.327, n.1-2, p.7377, 2006.

ARDITTY, S.; SCHMITT, V.; GIERMANSKA-KAHN, J.; LEAL-CALDERON, F. Materials based on solid-stabilized emulsions. J. Colloid Interface Sci., v.275, n.2, p.659-664, 2004.

CANNELL, J.S. Fundamentals of stability testing. Int. J. Cosmet. Sci., v.7, n.6, p.291-303, 1985.

CHANAMAI, R.; MCCLEMENTS, D.J. Dependence of creaming and rheology of monodisperse oil-in-water emulsions on droplet size and concentration. Colloids Surfaces A: Physicochem. Eng. Asp.,v.172, n.1-3, p.79-86, 2000
CORRÊA, N.M.; JÚNIOR, F.B.C.; IGNÁCIO, R.F.; LEONARDI, G.R. Rheologic behavior of different hydrophylic gels. Rev. Bras. Ciênc. Farm., v.41, n.1, p.73$78,2005$.

DEVILLERS, C.; PIÉRARD-FRANCHIMONT, C.; SCHREDER, A.; DOCQUIER, V.; PIÉRARD, G.E. High resolution skin colorimetry, strain mapping and mechanobiology. Int. J. Cosmet. Sci., v.32, n.4, p.241-245, 2010.

EPSTEIN, H. Cosmeceutical vehicles. Clin.Dermatol., v.27, n.5, p.453-460, 2009.

ESTANQUEIRO, M.; BOSSOLANI, G.; AMARAL, H.M.; CONCEIÇÃO, J.; SANTOS, D.; SILVA, J.B.; GOMES, C.; LOBO, J.M.S. Characterizing and evaluating the effectiveness of volcanic pumice exfoliants. Cosmet. Toiletries, v.127, n.11, p.780-792, 2012

GASPAR, L.R.; CAMPOS, P.M.B.G.M. Rheological behavior and the SPF of sunscreens. Int. J. Pharm., v.250,n.1, p.3544, 2003.

INTERNATIONAL Conference on Harmonization. Guideline for stability testing of new drug substances and products. Geneve: ICH, 2003.n.p.

JONES, D.S.; WOOLFSON, A.D.; BROWN, A.F. Textural analysis and flow rheometry of novel, bioadhesive antimicrobial oral gels. Pharm. Res.,v.14, n.4, p.450-457, 1997.

LABA, D. Rheological properties of cosmetic and toiletries. New York: Marcel Dekker, 1993. 440p.

LAGALY, G.; REESE, M.; ABEND, S. Smectites as colloidal stabilizers of emulsions: I. Preparation and properties of emulsions with smectites and nonionic surfactants. Appl. Clay Sci., v.14,n.1-3, p.83-103, 1999.

LEMAITRE-AGHAZARIAN, V.; PICCERELLE, P.; REYNIER, J.P.; JOACHIM, J.; PHAN-TAN-LUU, R.; SERGENT, M. Texture optimization of water-in-oil emulsions. Pharm. Dev. Technol., v.9,n.2, p.125-134, 2004.

ONDRACEK, J.; BOLLER, F.H.; ZULLIGER, H.W.; NIEDERER, R.R. Comparison among five methods for testing the physical stability of $\mathrm{O} / \mathrm{W}$ emulsions. Acta Pharm. Technol., v.31,s.n., p.42-48, 1985. 
PICHOT, R.; SPYROPOULOS, F.; NORTON, I.T. Mixedemulsifier stabilised emulsions: investigation of the effect of monoolein and hydrophilic silica particle mixtures on the stability against coalescence. J. Colloid Interface Sci., v.329,n.2, p.284-291, 2009.

SAVARY, G.; GRISEL, M.; PICARD, C. Impact of emollients on the spreading properties of cosmetic products: a combined sensory and instrumental characterization. Colloids Surfaces B Biointerfaces, v.102, p.371-378, 2013.

SHI, L.; MILLER, C.; CALDWELL, K.D.; VALINT, P. Effects of mucin addition on the stability of oil-water emulsions. Colloids Surfaces B Biointerfaces, v.15,v.3-4, p.303-312, 1999.
TADROS, T. Application of rheology for assessment and prediction of the long-term physical stability of emulsions. Adv. Colloid Interface Sci., v.108-109, p.227-258, 2004.

TAMBURIC, S.; CRAIG, D.Q.M.; VULETA, G.; MILIC, J. An investigation into the use of thermorheology and texture analysis in the evaluation of W/O creams stabilized with a silicone emulsifier. Pharm. Dev. Technol., v.1,n.3, p.299306, 1996.

TORRES, L.G.; ITURBE, R.; SNOWDEN, M.J.; CHOWDHRY, B.Z.; LEHARNE, S.A. Preparation of o/w emulsions stabilized by solid particles and their characterization by oscillatory rheology. Colloids Surfaces A: Physicochem. Eng. Asp., v.302,n.1-3, p.439-448, 2007.

Received for publication on $18^{\text {th }}$ July 2013 Accepted for publication on $13^{\text {th }}$ September 2013 
